\title{
Mund-Nasen-Schutz in der Öffentlichkeit: Keine Hinweise für eine Wirksamkeit
}

Ines Kappstein

\begin{abstract}
Etwa gleichzeitig mit den ersten Lockerungen des Lockdowns im Rahmen der
Corona-Pandemie wurde Ende April 2020 von allen Bundesländern in Deutschland eine Maskenpflicht für den ÖPNV und für Geschäfte eingeführt, und das nicht zuletzt aufgrund der „Neubewertung“ durch das Robert Koch-Institut (RKI)

[1]. In diesem Beitrag soll die Empfehlung des RKI bewertet werden.
\end{abstract}

\section{Die Empfehlung des \\ Robert Koch-Instituts}

Das RKI empfiehlt im Epidemiologischen Bulletin Nr. 19/2020

„... ein generelles Tragen einer Mund-Nasen-Bedeckung (MNB) in bestimmten Situationen im öffentlichen Raum als einen weiteren Baustein, um Risikogruppen zu schützen und den Infektionsdruck und damit die Ausbreitungsgeschwindigkeit von COVID-19 in der Bevölkerung zu reduzieren“.

[Diese Empfehlung beruhe] „auf einer Neubewertung aufgrund der zunehmenden Evidenz, dass ein hoher Anteil von Übertragungen unbemerkt erfolgt, und zwar bereits vor dem Auftreten von Krankheitssymptomen “. [1]

\section{Virusausscheidung vor den ersten Symptomen}

Dass infizierte Personen bereits vor Beginn der Krankheitssymptome (potenziell) infektiös sind (und in der Regel dabei sogar mehr Viren ausscheiden als während der symptomatischen Phase der Erkrankung), ist von anderen Virusinfektionen bekannt, deren Erreger ebenfalls über das respiratorische Sekret ausgeschieden werden (z.B. Influenza, Masern). Dass dies bei COVID-19 (Coronavirus Disease 2019) auch der Fall ist, war deshalb für die Fachwelt zu erwarten. Ebenso gilt dies für alle respiratorischen Infektionen, die asymptomatisch verlaufen (z. B. bei Influenza in ca. 1/3 der Fälle, s. RKIRatgeber [2]). Es sind also auch diese Personen für ihre Umgebung (potenziell) infektiös. Es gilt aber z. B. auch für gastrointestinale Infektionen, insbesondere verursacht durch Noroviren [3]. Insgesamt ist die Virusausscheidung vor Beginn der klinischen Erkrankung nichts Neues, sondern hätte auch bei COVID-19 von Anfang an in die Überlegungen eingeschlossen werden können.

\begin{abstract}
Merke
Bei zahlreichen Virusinfektionen beginnt die Infektiosität nicht erst mit Beginn der klinischen Symptome, vielmehr können infizierte Personen schon am Ende der Inkubationszeit Viren ausscheiden und dies noch dazu in hoher Zahl, wenn sie noch nicht ahnen, dass sie eine Infektion haben.
\end{abstract}

\section{Fremdschutz}

Über den möglichen Nutzen von Masken zum Schutz der Mitmenschen vor klinisch gesunden, aber bereits infizierten und damit potenziell infektiösen Menschen entwickelte sich im Frühjahr 2020 eine Diskussion in der Fachöffentlichkeit darüber, dass Masken nicht aus Eigenschutz, sondern aus „Altruismus“ getragen werden sollen [4]. Letztlich führte dies zu der MNB-Emp-

\begin{tabular}{ll}
\hline ABKÜRZUNGEN \\
BfArM & $\begin{array}{l}\text { Bundesinstitut für Arzneimittel und Medizinpro- } \\
\text { dukte }\end{array}$ \\
CDC & Centers for Disease Control and Prevention \\
COVID-19 & Coronavirus Disease 2019 \\
DGP & Deutsche Gesellschaft für Pneumologie \\
ECDC & European Centre for Disease Prevention and \\
& Control \\
FFP & Filtering Face Piece \\
HDM & Händedesinfektionsmittel \\
MERS & Middle East respiratory Syndrome \\
MNB & Mund-Nasen-Bedeckung \\
MNS & Mund-Nasen-Schutz \\
NRR & Nasen-Rachen-Raum \\
ÖPNV & Öffentlicher Personennahverkehr \\
PCR & Polymerasekettenreaktion \\
RKI & Robert Koch-Institut \\
SARS-CoV-2 & severe acute respiratory Syndrome \\
& Coronavirus 2 \\
WHO & World Health Organization
\end{tabular}


fehlung des RKI, bei der es um Fremdschutz und nicht um den Eigenschutz, z. B. von Risikogruppen, geht. Das RKI empfiehlt Masken in der Öffentlichkeit, damit der Träger der Maske, der vielleicht bereits unbemerkt infiziert ist und den Erreger schon im respiratorischen Sekret ausscheidet, seine respiratorischen Tröpfchen nicht ungehindert, z.B. beim Sprechen, freisetzen kann, die durch die MNB zu einem wesentlichen Teil zurückgehalten werden; dies mit dem Ziel, den Kontakt anderer Menschen mit dem Erreger zu verhindern. Alle Menschen sollen also eine MNB tragen, um damit die Risikopopulation vor einem Erregerkontakt zu schützen.

Ob das Ziel des „Fremdschutzes“ allerdings allen Bürgern klar ist, darf bezweifelt werden. International wird, was das RKI „Fremdschutz“ - im Gegensatz zum Eigenschutz - nennt, als „Source Control“ bezeichnet, es soll also die potenzielle Erregerquelle (=die infizierte Person) unter Kontrolle gehalten werden.

\section{Wissenschaftliche Grundlagen}

Im Folgenden soll zunächst der im Beitrag des RKI aufgeführte „fachliche Hintergrund“ dargestellt werden:

\section{Studie aus Hongkong}

Im Zusammenhang mit der Darstellung der Unterschiede von Mund-Nasen-Schutz (MNS) und FFP-Masken für den medizinischen Bereich wird auf eine „aktuelle“ Studie verwiesen, in der, wie es im RKI-Beitrag heißt, gezeigt werden konnte, „dass auch (ein) MNS zu einer relevanten Reduktion der Ausscheidung von Atemwegsviren über die Ausatemluft führt (...)“. Diese Studie aus Hongkong wurde jedoch bereits zwischen 2013 und 2016 durchgeführt, war also nicht aktuell, sondern wurde im Frühjahr 2020 zur Zeit der Corona-Pandemie nur aktuell publiziert [5].

In dieser Untersuchung wurden medizinische MNS (professionelle OP-Masken) verwendet. Teilnehmer der Studie waren 246 Patienten, die mit respiratorischen Symptomen unterschiedlicher Ursache (verursacht durch Influenzaviren, Rhinoviren oder saisonale humane Coronaviren) in eine Klinik in Hongkong kamen. Die Patienten wurden gebeten, als Probanden an einer Untersuchung teilzunehmen, in der das Ausmaß der Freisetzung von virushaltigen respiratorischen Tröpfchen und Aerosol in der Ausatemluft untersucht werden sollte. Die Viren wurden durch RNA-Nachweis mittels PCR nachgewiesen, teilweise durch Anzucht in Zellkulturen.

Randomisiert bekamen die Probanden entweder einen MNS oder nicht, um zu ermitteln, inwieweit der MNS einen Einfluss auf die Freisetzung der (jeweiligen) Viren habe, die Virusabgabe in die Umgebung also reduzie- ren würde. An sich war geplant, alle Probanden jeweils einmal mit und einmal ohne MNS zu untersuchen, jedoch lehnten die meisten ( $80 \%$ ) eine zweite Untersuchung aus Zeitgründen ab. Für die Untersuchung wurden nämlich die ausgeatmeten Partikel während 30 (!) Minuten gesammelt und unterteilt in die zwei Fraktionen

1. $>5 \mu \mathrm{m}$ ( = respiratorische Tröpfchen) und

2. $<5 \mu \mathrm{m}(=$ Aerosol).

Obwohl alle Probanden eine floride Virusinfektion der oberen Atemwege hatten (mit Konzentrationen von $10^{7-8}$ Viruskopien pro Probe im Nasensekret und von ca. $10^{4}$ Viruskopien pro Probe im Rachensekret), wurden jedoch ohne MNS nur bei 6 von 23 (Influenzaviren), bei 9 von 32 (Rhinoviren) bzw. bei 3 von 10 (Coronaviren) der genommenen Proben virushaltige Tröpfchen nachgewiesen, während virushaltige Aerosole unter denselben Bedingungen, d.h. ohne MNS, auch nur bei 8 von 23 (Influenzaviren), bei 19 von 34 (Rhinoviren) und bei 4 von 10 (Coronaviren) der Proben nachgewiesen wurden.

Dass trotz akuter Virusinfektion der oberen Atemwege und ohne MNS nur so wenige Proben überhaupt einen Virusnachweis erbrachten, ist ein bemerkenswertes Ergebnis der Studie, weil es zeigt, dass - anders als man gemeinhin annimmt - eine Person mit akuter Virusinfektion der oberen Atemwege offenbar keine „Virenschleuder" ist bzw. sein muss. Allerdings kommt noch hinzu, dass in den Proben, in denen überhaupt Virus nachgewiesen wurde (mit und ohne MNS), die Viruskonzentration in respiratorischen Tröpfchen und in Aerosol durchweg extrem niedrig war, sodass durch den MNS lediglich die „Ausreißerwerte“ ausgeglichen werden konnten.

In Anbetracht der effizienten Sammeltechnik und der (langen) Sammeldauer von 30 Minuten schlossen die Autoren deshalb aus ihren Ergebnissen, dass wahrscheinlich ein längerer enger Kontakt erforderlich sei, damit es überhaupt zu einer Erregerübertragung kommen kann. Dass bei den Proben mit Maske bei denjenigen Probanden, die überhaupt Virus ausschieden, die Virusfreisetzung durch die Maske reduziert wurde, ist ein zu erwartendes Ergebnis.

Jedoch stellt sich bei der Betrachtung der gesamten Studienergebnisse die Frage, welche praktische Relevanz ein MNS eigentlich haben sollen: Wenn nämlich (1) ein Großteil der infizierten Personen auch ohne MNS gar kein Virus freisetzt und wenn dann (2) noch dazu bei denjenigen mit Virusausscheidung die Viruskonzentrationen äußerst gering sind, spricht insgesamt wenig für einen Nutzen von MNS. Die Autoren stellen jedoch trotz der eigenen klaren Analyse fest, dass ihre Ergebnisse nahelegen, dass MNS (als OP-Mas- 
ke wie in der Studie verwendet) von kranken Personen verwendet werden könnten. Wohlgemerkt sprechen sie aber nur von kranken, also symptomatischen Personen und keineswegs von jedem Bürger im öffentlichen Raum. Um diese Frage ging es allerdings auch in dieser Studie nicht-entgegen dem Eindruck, den man beim Lesen des RKI-Beitrags gewinnen kann.

Nach Ansicht der Autoren sind ihre Ergebnisse nur eingeschränkt aussagefähig, weil bei einem großen Anteil der Probanden - unabhängig von der Art ihrer Virusinfektion - auch ohne MNS keine Virusfreisetzung nachgewiesen werden konnte, und dies trotz der (langen) Messdauer von 30 Minuten. Ein weiteres Defizit sehen sie darin, dass nicht untersucht wurde, ob die (in niedriger Konzentration) freigesetzten Viren auch infektiös waren (dies wurde nur bei Influenzavirus in Aerosol mittels Zellkultur überprüft und teilweise bestätigt).

\section{Merke}

Ob ein Erregernachweis außerhalb des Körpers bedeutet, dass die gefundenen Erreger auch ein tatsächliches Infektionsrisiko darstellen, ist kaum zu beantworten. Hinzu kommt, dass der Nachweis von Virusnukleinsäure kein Beleg für die Infektionstüchtigkeit von Viren ist. Auch ein Virusnachweis mittels Zellkultur ist nicht mit dem Nachweis ihrer Infektiosität unter normalen Lebensumständen gleichzusetzen.

\section{Fazit aus der Studie aus Hongkong}

\section{Geringe Virusfreisetzung}

Obwohl genau dafür als Beleg im Beitrag des RKI zitiert, liefert die Studie keinen Hinweis darauf, dass das generelle Tragen von MNB (ob professioneller MNS oder sog. Community-Masken) im öffentlichen Raum (Geschäfte, ÖPNV) das Risiko einer Infektion für die Personen reduzieren kann, denen man währenddessen begegnetdies allerdings mit Kontaktzeiten, die im Vergleich zu der Messdauer in der Studie von 30 min in aller Regel deutlich kürzer sind [5]. Die Studienergebnissen zeigen, dass das Risiko, mit ausgeschiedenen Viren anderer Menschen in Kontakt zu kommen, noch einmal sehr viel geringer und wahrscheinlich zu vernachlässigen ist, wenn man nicht direkt angehustet wird, eine Situation, die die meisten Menschen in Geschäften oder im ÖPNV kaum je wirklich erlebt haben werden, auch wenn gerade eine solche Situation als Risiko und damit als (eine) Begründung für MNB angeführt wird.

\section{Kurze Kontakte}

Bei Begegnungen im öffentlichen Raum handelt es sich von der Lebenserfahrung her nur in wenigen Fällen um enge ( $<1 \mathrm{~m}$ ) und längerdauernde ( $\geq 15 \mathrm{~min}$ ) Face-to-Face-Kontakte, um die es bei der Tröpfchenübertragung geht, die sich aber (im Gegensatz zur Patientenversorgung im Krankenhaus) in aller Regel nicht über 15 min oder mehr erstrecken. Wenn man z. B. einen Bekannten trifft, mit dem man länger reden möchte, dann kann man eigenverantwortlich Abstand wahren, sodass eine Erregerübertragung nicht zustande kommen kann. Meist aber geht man in der Öffentlichkeit nur kurz aneinander vorüber (z. B. Gang im Supermarkt) oder steht hintereinander (z. B. Kasse im Supermarkt) oder nebeneinander (z.B. ÖPNV). Und selbst wenn die Fahrt mit dem ÖPNV nicht nur wenige Minuten dauert, kann man sich erfahrungsgemäß nahezu immer so positionieren, dass man keinen Face-to-Face-Kontakt mit anderen Fahrgästen hat, auch wenn das Verkehrsmittel voll sein sollte. Abstand bei Gesprächen zu wahren, z. B. bei Bankgeschäften oder bei einer Beratung, z. B. in einem Buchladen, ist immer möglich - und macht Masken überflüssig.

\section{Face-to-face-Kontakt}

Dass der bei der Tröpfchenübertragung entscheidende Face-to-Face-Kontakt im Verlauf der „Coronakrise“ irgendwann quasi „verloren“ gegangen ist (zu Beginn der Pandemie jedenfalls war beim RKI und in den Medien noch ständig von mindestens 15-minütigem Face-to-Face-Kontakt als Voraussetzung für eine Erregerübertragung die Rede) und durch einen Rund-um-Abstand von mindestens 1,5 m ersetzt wurde, ist ein wichtiger Faktor für die zahlreichen Missverständnisse und Fehlinterpretationen: Nicht selten reagieren manche Menschen ängstlich, wenn jemand von irgendeiner Seite „zu nahe“ kommt.

\section{Einschätzung der WHO}

Die WHO (World Health Organization) hatte 2019 nicht-medizinische MNS nur mit Vorbehalt zum Schutz der Allgemeinbevölkerung bei schweren Epi- und Pandemien und chirurgische Masken für symptomatische Personen bei Kontakt mit anderen Menschen empfohlen, obwohl es keine wissenschaftliche Evidenz dazu gebe, ob diese Maßnahme effektiv sei, um Erregerübertragungen zu reduzieren. Vielmehr beruhe die potenzielle Effektivität auf Plausibilität [6]. In der (zum Zeitpunkt der Abfassung dieses Beitrags aktuellsten) Empfehlung vom Juni 2020 schreibt die WHO im Zu-

\section{DEFINITION}

\section{Tröpfchenübertragung}

- Übertragung von Erregern durch von anderen Personen freigesetzte respiratorische Tröpfchen auf die Schleimhäute der oberen Atemwege (Augen, Nase, Mund)

- Partikelgröße von respiratorischen Tröpfchen: $>5 \mu \mathrm{m}$

- Face-to-Face-Kontakt mit geringem Abstand (<1 m)

- Längere Kontaktdauer $\geq 15$ min 


\section{INFOBOX}

\section{Entscheidungskriterien gemäß WHO-Empfehlung}

Folgende Kriterien (jeweils mit einer Interpretation der Autorin, ob damit eher Fremd- oder Eigenschutz bzw. beides angestrebt ist) sollten nach den WHO-Empfehlungen bei einer solchen Entscheidung berücksichtigt werden, um zu einer risikobasierten Vorgehensweise zu kommen:

\section{- Zweck der Masken:}

- Festlegung, ob Fremdschutz oder Eigenschutz (oder beides) das Ziel ist

- Bei erhöhtem Expositionsrisiko:

- beschrieben als weitverbreitete Übertragungen in der Öffentlichkeit (ohne lokalisierbare Ausbrüche), aber nur begrenzten (oder nicht vorhandenen) Möglichkeiten für andere Maßnahmen zur Eindämmung (z. B. physische Distanz, Kontaktverfolgung, Durchführung von Tests mit Isolierung und Versorgung von Verdachts- oder bestätigten Fällen) oder aber in bestimmten beruflichen Situationen, in denen enger Kontakt mit Menschen besteht, z. B. als Sozialarbeiter oder Kassierer (vorwiegend Fremdschutz, berufsbedingt ggf. auch Eigenschutz)

- Bei Personen mit gesundheitlich erhöhtem Risiko:

- dann medizinische MNS, z. B. für ältere Menschen, bei Immunsuppression und für Menschen mit Herz-KreislaufKrankheiten, Diabetes mellitus, chronischer Lungenkrankheit, Karzinom und zerebrovaskulären Erkrankungen (Eigenschutz)

- In bestimmten (Lebens-)Situationen:

- hohe Populationsdichte (in Flüchtlingsheimen, bei beengten Wohnverhältnissen) und in Situationen (z. B. ÖPNV), in denen ein Abstand von mindestens $1 \mathrm{~m}$ nicht eingehalten werden kann (am ehesten Fremd- und Eigenschutz)

- Machbarkeit:

- Verfügbarkeit und Kosten von Masken

- Möglichkeit zum Waschen nicht-medizinischer Masken

- Eignung des Maskenträgers, die nachteiligen Auswirkungen beim Tragen von Masken zu tolerieren

- Maskentyp: medizinische oder nicht-medizinische Maske

Die WHO führt dazu aus, dass Regierungsentscheidungen, den Gebrauch von Masken zu empfehlen (oder zur Pflicht zu machen), diese Kriterien berücksichtigen sollen - zusammen mit dem lokalen Kontext, den kulturellen Bedingungen, der Verfügbarkeit von Masken, den erforderlichen Hilfsmitteln und den Neigungen der Bevölkerung.

sammenhang mit COVID-19 zu Masken in der Öffentlichkeit (wie bereits in der vorangegangenen Empfehlung vom April), dass es derzeit keine wissenschaftlichen Daten gebe, dass das Tragen von Masken (medizinische MNS bis hin zu sog. Community-Masken) durch (anscheinend) gesunde Personen im öffentlichen Setting vor Infektionen mit respiratorischen Viren, inkl. COVID-19, schützen könne [7].
In dieser neuen Empfehlung geht die WHO (neben dem Gebrauch von Masken im medizinischen Bereich) erstmals ausführlich auf den Gebrauch von Masken durch die Bevölkerung im öffentlichen Raum ein und macht dazu sehr differenzierte Angaben. Danach solle in bestimmten Situationen des öffentlichen Lebens das Tragen von Masken gefördert werden (ist also von der WHO nicht als „Vorschrift“ oder „Pflicht“ gedacht). Diese Empfehlung gibt die WHO aber nur für Gebiete (z.B. Landkreise) mit bekannter oder vermuteter ausgedehnter Übertragung (außerhalb von lokalisierbaren Ausbrüchen) in Situationen (z. B. ÖPNV), in denen Abstandhalten schwierig ist. Damit sei dies eine zusätzliche Maßnahme und Teil eines umfassenden Vorgehens, um die Übertragung von SARS-CoV-2 zu unterdrücken. Die WHO stellt fest, dass es dafür keine direkte wissenschaftliche Evidenz gebe und dass neben möglichen Vorteilen auch Nachteile zu nennen seien.

Wenn Masken für die Bevölkerung im öffentlichen Raum empfohlen werden, sollen die Entscheidungsträger folgende Punkte berücksichtigen:

- Der Zweck der Maske soll klar kommuniziert werden, d. h. wo, wann, wie und welcher Maskentyp getragen werden soll. Es solle erklärt werden, was mit Masken erreicht werden könne und was nicht. Ferner solle klargestellt werden, dass die Maske nur ein Teil eines Maßnahmenpaketes sei zusammen mit Händehygiene, physischer Distanz u.a., die alle notwendig seien und sich gegenseitig verstärken sollen.

- Die Menschen sollen darüber informiert und darin trainiert werden, wann und wie Masken sicher verwendet, d. h. angelegt, getragen, abgelegt, gereinigt und entsorgt werden.

- Die Umsetzbarkeit des Gebrauchs, Versorgungsund Nachschubfragen, soziale und psychologische Akzeptanz (sowohl des Tragens und des Nicht-Tragens verschiedener Maskentypen unter unterschiedlichen Bedingungen) sollen berücksichtigt werden.

- Es sollen fortlaufend wissenschaftliche Daten und Evidenz über die Effektivität des Maskengebrauchs (inkl. verschiedener Maskentypen oder von anderen Gesichtsbedeckungen wie Tücher) gesammelt werden.

- Die Auswirkungen (positiv, neutral oder negativ) des Maskengebrauchs in der allgemeinen Bevölkerung sollen ausgewertet werden (inkl. Verhaltens- und Sozialwissenschaft). 


\section{INFOBOX}

\section{Potenzielle Vor- und Nachteile von „Alltagsmas- ken" gem. WHO \\ Vorteile}

Als potenzielle Vorteile, wenn gesunde Menschen in der Öffentlichkeit Masken tragen, führt die WHO folgende Gründe auf:

- reduziertes potenzielles Expositionsrisiko ausgehend von infizierten, noch nicht symptomatischen Personen

- reduzierte potenzielle Stigmatisierung von Personen, die Masken zum Fremdschutz tragen, oder von Personen, die im nicht-klinischen Bereich für Patienten mit COVID-19 sorgen

- Stärkung des Gefühls in der Bevölkerung, dazu beitragen zu können, die Ausbreitung des Virus zu beenden

- Erinnerung daran, andere Maßnahmen zu beachten, wie Händehygiene, Vermeidung eigener HandGesichts-Kontakte, obwohl dies auch den gegenteiligen Effekt haben könne (s.u. bei „Nachteile“)

- potenzielle soziale und ökonomische Vorteile, z. B. durch Herstellung von Masken, wodurch eine Einkommensquelle geschaffen und dadurch eine bessere Integration erreicht werden könne etc.

\section{Nachteile}

Die WHO nennt die folgenden potenziellen Nach-

teile, wenn gesunde Menschen in der Öffentlichkeit Masken tragen:

- potenziell erhöhtes Risiko der Selbstkontamination infolge von Manipulationen an der Maske und anschließendem Kontakt der Augen mit den kontaminierten Händen

- potenzielle Selbstkontamination, falls nicht-medizinische Masken nicht gewechselt werden, wenn sie feucht oder verschmutzt sind, weil dadurch günstige Bedingungen für die Vermehrung von Mikroorganismen geschaffen werden können

- potenziell Kopfschmerzen und/oder Atemprobleme abhängig von der Art der Maske

- potenziell Entwicklung von Hautläsionen oder -irritationen, Verschlimmerung von Akne bei häufigem Gebrauch über längere Zeit

- Schwierigkeiten mit einer klaren Aussprache

- potenziell unangenehmes Gefühl

- falsches Gefühl von Sicherheit mit der möglichen Folge einer geringeren Beachtung anderer wichtiger Präventionsmaßnahmen, wie z. B.

- physische Distanz und

- Händehygiene

- mangelnde Umsetzung des Maskentragens (insbesondere kleinere Kinder)

- Abfallprobleme, wenn Masken im öffentlichen Raum falsch entsorgt und die Abfallbehälter zu voll werden (dadurch Kontaminationen beim Entsorgungspersonal und in der Umgebung möglich)

- Schwierigkeit für Menschen mit Hörstörungen, da diese auf das Ablesen von den Lippen angewiesen sind

- Probleme, die Maske zu tragen, insbesondere

- bei Kindern,

- bei Menschen mit psychiatrischen Erkrankungen,

- bei älteren Menschen mit kognitiven Einschränkungen,

- bei Personen mit Asthma oder chronischen respiratorischen oder Atemproblemen,

- bei Personen nach Gesichtsverletzungen oder kürzlichen Operation im HNO-Bereich

- bei Menschen, die in heißer und feuchter Umgebung leben

\section{Stoffmasken nur für Fremdschutz geeignet}

Es werden von der WHO außerdem die verschiedenen Maskenarten diskutiert und in Hinsicht auf Stoffmasken festgehalten, dass sie nur für den Fremdschutz in Betracht gezogen werden sollen, ihr Gebrauch solle aber immer von häufiger Händehygiene und physischem Abstandhalten begleitet sein.

\section{Einschätzung des European Centre for Disease Prevention and Control (ECDC)}

Das ECDC (European Centre for Disease Prevention and Control) macht zur potenziellen Effektivität von Masken gegen die Übertragung des Erregers von COVID19 nur vage Angaben und beruft sich u. a. auf die Stellungnahme der WHO von 2019 [6,8]. Es gebe eine begrenzte indirekte Evidenz dafür, dass nicht-medizinische Masken (aus verschiedenen Materialien) die Frei- setzung respiratorischer Tröpfchen in die Umgebung beim Husten reduzieren können, die verfügbare Evidenz lege aber nahe, dass nicht-medizinische Masken bei der Kontrolle der Erregerquelle („Source Control“) weniger effektiv seien als medizinische Masken.

Man könne auch nicht etwa aus der Tatsache schließen, dass in asiatischen Ländern, in denen das Tragen von Masken in der Öffentlichkeit häufig sei, deshalb die Corona-Infektionsraten in manchen dieser Länder niedriger seien-denn es gebe dort neben dem Gebrauch von Masken zahlreiche weitere Maßnahmen, die praktiziert werden, um das Infektionsrisiko zu reduzieren. Beispielsweise sei in diesen Ländern das Bewusstsein für die sog. respiratorische Etikette und für die Händehygiene stärker ausgeprägt als anderswo. 
PRAXIS

\section{Genereller Umgang mit Masken}

Zum generellen Umgang mit Masken macht die WHO folgende Angaben:

- Masken sollen immer nur von einer Person benutzt werden.

- Sie sollen gewechselt werden, wenn sie feucht oder sichtbar verschmutzt sind. Eine feuchte Maske soll nicht für längere Zeit getragen werden.

- Beim Abnehmen der Maske soll sie an der Außenseite nicht berührt werden. Augen, Nase und Mund sollen unmittelbar danach nicht berührt werden.

- Nach dem Abnehmen soll die Maske entweder sofort entsorgt oder in einen verschließbaren Beutel verbracht werden, bis sie gewaschen wird. Unmittelbar nach der Versorgung der Maske sollen die Hände gewaschen werden.

- Stoffmasken sollen häufig gewaschen und sorgfältig gehandhabt werden, um andere Gegenstände nicht zu kontaminieren. Schon bei der Wahl des Stoffes soll darauf geachtet werden, dass die Masken bei mindestens $60^{\circ} \mathrm{C}$ gewaschen werden können.

Der Gebrauch von (nicht-medizinischen) Masken in der Öffentlichkeit könne in erster Linie als Mittel der „Source Control“ dienen, auch wenn nicht klar sei, inwieweit dieses Ziel überhaupt erreichbar ist, solle aber nur als eine zusätzliche Maßnahme in Betracht gezogen werden, jedoch nicht als Ersatz für die zentralen Präventionsmaßnahmen, zu denen u.a. sorgfältige Händehygiene sowie die Vermeidung von eigenen Hand-Gesichts-Kontakten (Augen, Nase, Mund) gehörten.

Zusammenfassend sagt das ECDC, dass bei der Empfehlung für den Gebrauch von Masken in der Öffentlichkeit die Lücken in der wissenschaftlichen Evidenz und die möglichen negativen Auswirkungen sorgfältig in Betracht gezogen werden müssten. Sie sollen nur als ergänzende Maßnahme erwogen werden, dürften aber nicht dazu führen, dass die etablierten Maßnahmen insbesondere der sorgfältigen Händehygiene und der Vermeidung eigener Hand-Gesichts-Kontakte (Augen, Nase, Mund) beeinträchtigt werden.

\section{Empfehlung der Centers for Disease Control and Prevention (CDC)}

Die US-amerikanischen CDC äußern sich ähnlich wie WHO und ECDC, berufen sich aber nicht auf wissenschaftliche Evidenz, außer in Bezug auf die frühzeitige Erregerausscheidung am Ende der Inkubationszeit [9].

\section{INFOBOX}

Argumente für und gegen das Tragen von Masken gem. ECDC

\section{Argumente des ECDC gegen den Gebrauch von Masken}

- Es gibt einen Mangel an medizinischen Masken, weshalb ihre Verwendung primär dem Eigenschutz des medizinischen Personals vorbehalten bleiben soll.

- Es gibt nur eine begrenzte indirekte wissenschaftliche Evidenz dafür, dass nicht-medizinische Masken als Mittel der „Source Control“ effektiv sind.

- Das Tragen von Masken kann ein falsches Gefühl von Sicherheit erzeugen, wodurch es zu vermehrten Hand-Gesichts-Kontakten kommen kann, z. B. wenn die Maske zurechtgerückt wird.

- Masken müssen sorgfältig an- und wieder abgelegt werden, um Kontaminationen der Hände zu vermeiden.

- In bestimmten Bevölkerungsgruppen, z. B. bei Kindern oder Personen mit chronischen respiratorischen Krankheiten, werden Masken nicht gut toleriert.

- Es gibt keine etablierten Standards für nicht-medizinische Masken als Mittel für die „Source Control“ oder den persönlichen Schutz.
Argumente des ECDC für den Gebrauch von Masken

- Weil Personen mit milden Symptomen oder asymptomatische Personen zur Verbreitung des Erregers beitragen können, könnten Masken (oder andere Gesichtsbedeckungen) als Mittel der „Source Control“ in Ergänzung zu anderen Maßnahmen zur Reduktion der Übertragung der Viren in Erwägung gezogen werden. Es sei aber nicht klar, inwieweit die Verwendung von Masken in der Öffentlichkeit in Ergänzung zu den anderen Maßnahmen (z. B. Händehygiene) zu einer Reduktion der Erregerübertragung beitragen könne.

- Die Virusausscheidung ist am Ende der Inkubationszeit, also kurz bevor die Symptome auftreten, höher (wie ebenso in den ersten 7 Tagen nach Auftreten der Symptome).

- In asiatischen Ländern werden Masken in der Öffentlichkeit in breitem Maße verwendet und wurden während der SARS-Epidemie im Jahr 2003 mit einem niedrigeren Risiko bei Personen in Verbindung gebracht, die keinen bekannten Kontakt zu Patienten mit SARS hatten.

- Nicht-medizinische Masken und Stoffmasken haben den Vorteil, dass sie einfach hergestellt werden können. Stoffmasken sind außerdem waschbar und damit wiederverwendbar. 


\section{Aktualisierter Cochrane-Review}

In dem 2020 aktualisierten Cochrane-Review werden u. a. Studien zur Effektivität von Masken bei der Reduktion der Verbreitung respiratorischer Viren ausgewertet [10]. In diesen Studien ging es jedoch nicht um das Tragen von Masken in der Öffentlichkeit, wie es in Deutschland (und manchen anderen Ländern) für alle Bürger in bestimmten Situationen (Geschäfte, ÖPNV) zur Pflicht gemacht wurde. Vielmehr wurden Untersuchungen in ganz anderen Settings ausgewertet, und somit ist es irreführend, wenn es im Text des RKI-Beitrags, in dem es ja explizit um den Gebrauch von Masken in der Öffentlichkeit geht, dazu heißt:

„In einer Aktualisierung ihres Cochrane Reviews aus dem Jahre 2003 empfehlen die Autoren, basierend auf Beobachtungsstudien während des SARS-Ausbruchs, den Einsatz von Masken ebenfalls in Kombination mit anderen Maßnahmen“. [1]

Einbezogen wurde in den aktuellen Review von 2020 z. B. eine Untersuchung bei einem großen religiösen Treffen in Australien, bei dem überprüft werden sollte, ob das Tragen von Masken (professionelle chirurgische Masken) bei Teilnehmern mit respiratorischer Infektion die Erregerübertragung innerhalb solcher Massenveranstaltungen mit engem Kontakt (z.B. Aufenthalt in Zelten) zwischen den Teilnehmern reduzieren könne.

In eine andere Studie wurden von niedergelassenen Ärzten in Frankreich bei Hausbesuchen Haushalte aufgenommen, in denen es Influenzafälle gab. Die erkrankten Personen sollten eine (professionelle chirurgische) Maske tragen, die restlichen Mitglieder des Haushalts nicht. Ermittelt werden sollte die Rate der Übertragungen auf andere Mitglieder des Haushalts. Ebenso ging es in einer weiteren Studie aus Australien um den Effekt von Masken in Haushalten mit erkrankten Mitgliedern. Daneben gab es weitere Studien, in denen der Effekt von Händehygiene zusammen mit Masken untersucht wurde, so z. B. bei 2 Untersuchungen in Studentenwohnheimen, also in einer gewissermaßen großen Wohngemeinschaft.

Sämtlich waren es also Studien, die nichts-auch nicht im weiteren Sinne-mit dem Tragen von Masken in der Öffentlichkeit (Geschäfte, ÖPNV) zu tun haben. Die meisten der im Cochrane-Review zitierten Studien wurden darüber hinaus bei medizinischem Personal durchgeführt, weshalb sie für die Betrachtung hier keine Rolle spielen.
Fazit zu der vom RKI zitierten

wissenschaftlichen Grundlage für die Maskenempfehlung im öffentlichen

Raum

\section{Masken nicht Evidence-based}

Es gibt aus der im Beitrag des RKI zitierten Fachliteratur keine wissenschaftlich fundierten Hinweise, und das auch nicht aus den dort genannten „aktuellen“ Studien, dass Masken, die von der normalen Bevölkerung im öffentlichen Raum (Geschäfte, ÖPNV) getragen werden, ganz gleich welcher Art sie sind, also ob medizinische MNS oder sog. Community-MNB, die Erregerübertragung bei respiratorischen Infektionen, wie insbesondere Influenza oder COVID-19, reduzieren könnten, um damit „eine nachhaltige Reduktion der Ausbreitungsgeschwindigkeit von COVID-19 in der Bevölkerung und sinkende Neuerkrankungszahlen zu erreichen“, wie es im RKI-Beitrag heißt. Ebenso fehlen wissenschaftliche Belege, dass der zusätzliche Gebrauch von Masken in der Bevölkerung bewirken könnte, dass sich damit „mehrere Komponenten (...) gegenseitig ergänzen“ [1].

Dementsprechend heißt es im RKI-Beitrag u. a. sehr zurückhaltend: „Eine teilweise Reduktion dieser unbemerkten Übertragung von infektiösen Tröpfchen durch das Tragen von MNB könnte (Hervorhebung von der Autorin) auf Populationsebene zu einer weiteren Verlangsamung der Ausbreitung beitragen"- eine Formulierung, die im wissenschaftlichen Diskurs wegen offensichtlich fehlender Belege für eine Empfehlung mit weitreichenden Folgen eigentlich nicht hätte verwendet werden dürfen.

\section{Epidemiologischer Zusammenhang entscheidend}

Zwar führt das RKI in dem Beitrag an, dass „Ausbruchsuntersuchungen und Modellierungsstudien“ (zeigten), dass ...

„die rasche Ausbreitung von SARS-CoV-2 auf einem hohen Anteil von Erkrankungen beruhe, die initial mit nur leichten Symptomen beginnen, ohne die Erkrankten in ihrer täglichen Aktivität einzuschränken. Bereits 1-3 Tage vor Auftreten der Symptome kann es zu einer Ausscheidung von hohen Virusmengen kommen. Eine teilweise Reduktion dieser unbemerkten Übertragung von infektiösen Tröpfchen durch das Tragen von MNB könnte (Hervorhebung von der Autorin) auf Populationsebene zu einer weiteren Verlangsamung der Ausbreitung beitragen. “ [1]

Doch handelt es sich dabei, wie schon erwähnt, um bekannte Tatsachen, die nichts mit den angeblich neuen wissenschaftlichen Belegen für die Wirksamkeit von MNB im öffentlichen Raum zu tun haben. Außerdem spiegeln Ausbrüche, z. B. in Pflegeheimen oder in Un- 
INFOBOX

„Wie man in den Wald hineinruft, ...“: von „kann“ und „könnte“ zu „ist“"

Nachdem sich das RKI auf den ersten beiden Seiten nur eher vorsichtig zu den möglichen positiven Auswirkungen geäußert hat („könnte“, „kann“), spricht es in diesem letzten Satz mit „ist“, aber so, als ob das Tragen von MNB tatsächlich, also durch wissenschaftliche Untersuchungen bestätigt, ein solcher Baustein wäre; dies allerdings, ohne dass dafür eine wissenschaftliche Grundlage angeführt würde (und werden könnte).

Diese Formulierung am Ende des Beitrags mag für all die Leser (z. B. Journalisten) gewählt worden sein, die nur den letzten Satz (oder Absatz) eines Artikels lesen, weil dort oft ein (leicht lesbares) kurz gefasstes Resümee gegeben wird. Bei den Lesern hängen bleiben wird damit der Eindruck, dass eine positive Wirkung der Maskenempfehlung für den öffentlichen Raum eine „Tatsache“ darstellt - was jedoch gerade nicht der Fall ist.

terkünften für Asylbewerber bzw. Mitarbeiter in Schlachtbetrieben, eine völlig andere epidemiologische Situation wider als der Aufenthalt von Menschen im öffentlichen Raum, und Modellierungsstudien sind rein mathematisch-theoretischer Natur, deren Ergebnisse maßgeblich von den darin verwendeten Annahmen („Stellschrauben“) abhängen.

Und dennoch endet der Beitrag des RKI mit der Aussage:

„In dem System verschiedener Maßnahmen ist (sic!) ein situationsbedingtes generelles Tragen von MNB (oder MNS, wenn die Produktionskapazität dies erlaubt) in der Bevölkerung ein weiterer Baustein, um Übertragungen zu reduzieren“. [1]

\section{Keine wissenschaftlichen Daten}

Weder vom RKI oder von der WHO noch von ECDC oder CDC wurden wissenschaftliche Daten für eine positive Wirkung von Masken in der Öffentlichkeit (im Sinne einer reduzierten „Ausbreitungsgeschwindigkeit von COVID-19 in der Bevölkerung“ [1]) vorgelegt, weil es solche Daten nicht gibt [1,6-9]. Ebenso stützt auch das Update des Cochrane-Reviews die Anwendung von Masken im öffentlichen Raum in keiner Weise [10]. Dies wird durch 2 weitere Reviews der relevanten Literatur vom April 2020 bestätigt $[11,12]$. Dasselbe gilt für die schon vor einigen Jahren durchgeführte Studie aus Hongkong [5].

Die Deutsche Gesellschaft für Pneumologie (DGP) kommt in einer Stellungnahme vom Mai 2020 zur Auswirkung von Masken auf den Eigen- und Fremdschutz zu dem Schluss, dass „nicht-medizinische, aus Stoffen hergestellte Masken (...) einen Fremdschutzeffekt" haben [13]. Die darin zitierten experimentellen Maskenuntersuchungen zur Filterleistung verschiedener Maskentypen und -materialien lassen eine solche Schlussfolgerung nicht zu. Ebenso wenig wird dieses Resultat durch die zitierten epidemiologischen Studien gestützt, die auch Gegenstand der Untersuchung in dem aktualisierten Cochrane-Review waren [10].

In einer Anfang Juni 2020 publizierten Modellierungsstudie wird über den Effekt der Maskenpflicht am Beispiel der Stadt Jena sowie anderer Städte und Regionen in Deutschland berichtet [14]. Die Autoren (sämtlich Ökonomen) kommen zu dem Schluss, dass die Maskenpflicht zu einer ca. 40\%igen Reduktion der täglichen Zuwachsrate an COVID-19-Infektionen geführt habe. Unberücksichtigt bleibt in dieser Studie jedoch der entscheidende Aspekt, dass bereits ab dem 1. März 2020 (also knapp 5 Wochen vor der Einführung einer Maskenpflicht im öffentlichen Raum in der Stadt Jena) die Ausbreitungsrate von SARS-CoV-2 zurückging und dass am 10. März der R-Wert nach Angaben des RKI schon unter 1 lag $[15,16]$. Daraus folgt, dass die Einführung der Maskenpflicht (ab 6. April zunächst in Jena, etwa 3 Wochen später dann auch im gesamten Bundesgebiet) in eine Phase der Corona-Epidemie fiel, in der es schon zu einem kontinuierlichen und deutlichen Rückgang der Infektionszahlen gekommen war, eine Entwicklung, die sich anschließend weiter fortsetzte.

Einen Effekt der Maskenpflicht auf den Rückgang der Infektionszahlen kann man daraus nicht ableiten, weil sich beides überlagert, dies aber in der Modellierungsstudie nicht einbezogen wurde. Außerdem muss berücksichtigt werden, dass das Meldedatum der Fälle, das in der Studie verwendet wurde, keine auch nur annähernd sichere Aussage zulässt über den Zeitpunkt der Infektion, der sich nur über das Erkrankungsdatum (=Beginn der klinischen Symptomatik) genau genug festlegen lässt, wie es das RKI in seinen Modellierungsstudien praktiziert [16].

Gemäß RKI beträgt nämlich die Zeit zwischen Infektion und Meldedatum 14-21 Tage, und dieser Zeitraum setzt sich zusammen aus

1. der Inkubationszeit,

2. dem Zeitverzug, bis der Patient wegen zunehmender Symptome zum Arzt geht,

3. der Zeit für die Durchführung des Tests (inkl. Transport ins Labor und Auswertung im Labor),

4. den administrativen Verzögerungen bei der Meldung der Testergebnisse an das RKI sowie 5. der Publikation durch das RKI [15].

Die aktuelle Modellierungsstudie geht jedoch nur von einer Verzögerung von etwa 8 Tagen aus. Mit anderen Worten: Der in dieser Untersuchung der Maskenpflicht 
zugeschriebene Effekt beim Rückgang der Infektionszahlen wird zum einen überlagert vom deutlichen Rückgang der Infektionszahlen, der überall in Deutschland einige Wochen vor Einführung der Maskenpflicht in Jena und anderswo begonnen hatte. Zum anderen muss berücksichtigt werden, dass die jeweils dem RKI gemeldeten Infektionen 14-21 Tage zuvor entstanden sind, die Maskenpflicht also mindestens in den ersten 2-3 Wochen keinen Einfluss auf die Infektionszahlen gehabt haben kann.

Ein weiterer wichtiger Aspekt für die Beurteilung eines Effekts der Maskenpflicht ist, dass in den gemeldeten Infektionszahlen immer auch Infektionen verborgen sein können, die aus Ausbruchsgeschehen, z. B. in Heimen oder Krankenhäusern, stammen. Institutionelle Ausbrüche werden aber durch eine Maskenpflicht im öffentlichen Raum nicht beeinflusst, sodass ein Rückgang der Infektionszahlen in einem Ort bzw. in einer Region daran liegen kann, dass zuvor Ausbruchsgeschehen die Zahl der Infektionsfälle erhöht haben, danach aber die Fallzahlen durch das Fehlen weiterer Ausbrüche niedriger waren als vor der Einführung der Maskenpflicht. Ohne Berücksichtigung also, aus welchem epidemiologischem Zusammenhang die aus den verschiedenen Orten gemeldeten Infektionszahlen stammen (d.h. ob Ausbrüche darunter waren oder nicht), bleibt der Effekt von Masken in der Öffentlichkeit auf das Auftreten von Neuinfektionen notgedrungen unklar.

\section{Merke}

Insgesamt bringt auch diese neue Modellierungsstudie keine Ergebnisse, die eine Maskenpflicht stützen können.

Dasselbe gilt für eine weitere Modellierungsstudie, die für Wuhan (China), für Italien und für New York City gezeigt haben will, dass mit Einführung der Maskenpflicht in der Öffentlichkeit die Zahl der Neuinfektionen erheblich zurückging [17]. Allerdings haben - wie in [14] - auch diese Autoren (ebenfalls keine Mediziner, sondern Physiker und Chemiker) übersehen, dass die Auswirkungen einer Maßnahme nicht sofort erkennbar sind, sondern wegen des Intervalls zwischen dem Zeitpunkt der Infektion und dem Meldedatum frühestens ca. 2-3 Wochen danach erkennbar sein könnten. Bei einer weiteren Arbeit handelt es sich um eine rein theoretische Modellierungsstudie, deren Aussagekraft für die Realität völlig offen ist [18].

Auch der Anfang Juni 2020 erschienene systematische Review mit Metaanalyse liefert keine Hinweise [19]. Darin geht es - neben physischer Distanz und Augenschutz - zwar auch um Masken, aber nicht um das Tragen von Masken im öffentlichen Raum zum Fremdschutz. In den meisten dort behandelten 44 verglei- chenden Studien, die in die Metaanalyse eingeschlossen werden konnten, geht es um SARS bzw. MERS, in 7 davon um COVID-19, aber in keinem Fall um eine Untersuchung, die Rückschlüsse auf das Tragen von Masken im öffentlichen Raum aus Gründen des Fremdschutzes zuließe. Masken spielten sowieso nicht in allen der eingeschlossenen Untersuchungen eine Rolle, z. B. ging es manchmal auch nur um physische Distanz. Überwiegend waren es noch dazu Untersuchungen aus dem Bereich der Patientenversorgung in Krankenhäusern, nur 9 Studien sind aus anderen Lebensbereichen (Haushalte, nahe Kontaktpersonen, Flugzeug, Reisen) aufgeführt.

In einer einzigen Studie - über Risikofaktoren für SARS in Peking aus dem Jahr 2004 - ging es tatsächlich u.a. um das Tragen von Masken in der Öffentlichkeit, jedoch zum Schutz der Träger (Eigenschutz) und nicht zum Fremdschutz. Ein Ergebnis dieser Studie aus Peking war, dass Personen, die aus eigenem Antrieb ausschließlich mit Maske das Haus verließen, weil sie sich selbst schützen wollten, ein geringeres Risiko hatten, SARS zu akquirieren. Insofern trägt diese Studie zu Masken als Fremdschutz ebenfalls nichts bei.

Auch diese neue (im Übrigen von der WHO geförderte) systematische Übersichtsarbeit hat keine Untersuchungen zu Tage gefördert, die überhaupt eine oder sogar eine stützende Aussage zum Tragen von Masken im öffentlichen Raum erlauben würden.

\section{Resümee zur wissenschaftlichen Grundlage}

Trotz fehlender wissenschaftlicher Evidenz haben sowohI WHO, ECDC, CDC und RKI - allesamt in der Regel hochgeachtete nationale und internationale wissenschaftliche Gesundheitsbehörden - das Tragen von Masken im öffentlichen Raum empfohlen, wenn auch, wie bei der WHO [7], beschränkt auf spezielle epidemiologische Situationen, von allen aber mit deutlichen „Warnhinweisen“ versehen, mit der Folge, dass sich die Politik auf eben diese, aber ohne wissenschaftliche Grundlage vorgenommenen Einschätzungen beruft. Die „Warnhinweise“ jedoch beschränken sich dabei auf die Notwendigkeit, trotzdem Abstand zu wahren.

Man muss feststellen, dass alle nationalen und internationalen Gesundheitsbehörden entgegen der wissenschaftlich etablierten Standards der Evidence-based Medicine eine Einschätzung zum Tragen von Masken im öffentlichen Raum mit großer Tragweite abgegeben haben, die lediglich auf sog. plausiblen Überlegungen beruht, was jedoch nicht ausreichen kann, um der Politik in einer solchen Lage, d. h. für den Einsatz bei Millionen von Menschen, eine wissenschaftliche fundierte Entscheidungsbasis zu vermitteln. 
FAZIT

Community-Masken wegen Mangel an medizinischem Mund-Nasen-Schutz

Es ist klar, dass aufgrund des weltweiten Mangels an professionellen MNS (von denen es im Frühjahr 2020 in Kliniken und Pflegeheimen bei weitem nicht genug gab, sodass sie für die Nutzung der Bevölkerung in Deutschland ohnehin nicht in Frage kamen) die allgemeine Maskenpflicht in Deutschland nur eingeführt werden konnte mit dem Hinweis, dass selbstgenähte Masken oder auch nur ein Tuch vor Mund und Nase ebenfalls ausreichten.

Über die Qualität von MNB können naturgemäß keine Aussagen gemacht werden, weil jeder Bürger verwenden kann, was er will, eben z. B. nur ein Tuch oder einen Schal. Schon deshalb also kann es, wie im Beitrag des RKI angeführt, zu MNB keine Daten geben.

Transparent wäre es gewesen, auf das Fehlen von wissenschaftlichen Daten für den generellen Einsatz von MNB im öffentlichen Raum ausdrücklich hinzuweisen. Wenigstens hätte aber im letzten Satz des Artikels, wie überall zuvor im Text, nur davon gesprochen werden sollen, dass der MNB ein Baustein sein könnte, um Übertragungen zu reduzieren, nicht aber, dies als Tatsache zu formulieren.

\section{Voraussetzungen für den Gebrauch von Masken im öffentlichen Raum}

Maskenpflicht im öffentlichen Raum bedeutet, dass Masken von allen Menschen in Deutschland ab dem 7. Lebensjahr (also theoretisch von knapp 80 Millionen Menschen) getragen werden müssen, wenn sie in Geschäfte gehen oder mit dem ÖPNV fahren wollen. Ausgedehnt wurde diese Pflicht auf das gesamte öffentliche Leben: Lehrer und Schüler, Dozenten und Studenten, Friseure, Beschäftigte in der Autoindustrie, Handwerker, Servicepersonal in Gaststätten u.v.a.m., obwohl bei Face-to-Face-Kontakt entweder genügend Abstand gehalten werden kann oder auch nur ein kurzer Face-to-Face-Kontakt stattfindet, bei dem Erregerübertragungen sehr unwahrscheinlich sind.

\section{Merke}

Neben der fehlenden wissenschaftlichen Basis ist noch ein anderer Aspekt von Bedeutung: Es geht um den korrekten Umgang mit Masken (welcher Art auch immer), damit nicht durch die Masken selbst das Risiko für die Verbreitung des Erregers erhöht wird.

An 3 Stellen des (kurzen) Artikels weist auch das RKI eindringlich auf die Problematik im Zusammenhang mit der Anwendung von Community-Masken hin [1]:
... [dass] „der Einsatz von MNB die zentralen Schutzmaßnahmen, wie die (Selbst-)Isolation Erkrankter, die Einhaltung der physischen Distanz von 1,5 m, die Hustenregeln und die Händehygiene zum Schutz vor Ansteckung nicht ersetzen kann. Diese zentralen Schutzmaßnahmen müssen also weiterhin strikt eingehalten werden".

„Auch die hygienische Handhabung und die Pflege von MNB sind zu beachten. Aus diesem Grund ist darauf zu achten, dass die MNB - insbesondere beim Auf- und Absetzen - nicht berührt (Hervorhebung von der Autorin) wird, um eine Kontamination durch die Hände zu verhindern. Generell geht eine längere Tragedauer auch mit einer erhöhten Kontaminationsgefahr einher. “ (Hier wird auf die Hinweise des BfArM=Bundesinstitut für Arzneimittel und Medizinprodukte verwiesen; s.u. [20]).

„Dabei (d. h. bei den sich gegenseitig ergänzenden Komponenten, s. o.: Satzzuvor) sind immer die Wirksamkeit der ergriffenen Maßnahmen und deren unerwünschte Auswirkungen sorgsam gegeneinander abzuwägen. “

\section{Warum ist ein korrekter Umgang mit Masken wichtig?}

\section{Übertragung von Erregern respiratorischer Infektionen}

\section{Respiratorische Tröpfchen: keine Inhalation}

Bei der Erregerübertragung durch respiratorische Tröpfchen, zu der es in aller Regel nur bei nahem $(<1 \mathrm{~m})$ und längerdauerndem ( $\geq 15 \mathrm{~min}$ ) Face-to-FaceKontakt kommen kann, werden von einer infizierten Person, z. B. beim Sprechen oder Husten, potenziell infektiöse respiratorische Tröpfchen abgegeben [21, 21 23]. Diese Tröpfchen können anschließend auf die Schleimhäute von Augen, Nase und/oder Mund einer anderen Person treffen, wenn sie entsprechend nahe gegenübersteht. Daraus kann sich schließlich bei fehlender Immunität der anderen Person eine Infektion entwickeln, weil genau dort die Eintrittspforten für die respiratorischen Viren sind. Es handelt sich dabei um sog. große Tröpfchen (>5 $\mu \mathrm{m})$, die wegen ihrer Größe nicht in die tieferen Atemwege inhaliert werden können, sondern in den oberen Atemwegen quasi aufgefangen werden. Es geht also bei der Tröpfchenübertragung nicht um Inhalation.

Als Minimalrisiko kann man nach allem, was zur Tröpfchenübertragung seit Langem bekannt ist, zählen, dass es auch bei größerer Entfernung doch in seltenen Fällen zu einer Erregerübertragung kommen kann. Erregerübertragungen, ganz gleich mit welchen Erregern, lassen sich aber nie mit $100 \%$ iger Sicherheit vermeiden. Wenn man also auch Minimalrisiken verhindern will, lenkt man vom eigentlichen, nämlich weit überwiegenden Risiko ab. Und dies kann dann, wie bei der Masken- 
pflicht, sogar zu einer Situation eines generell erhöhten Risikos führen (s.u.).

Man muss sich bei all diesen Überlegungen eben immer vor Augen halten, dass es Menschen zwar schon seit sehr langer Zeit gibt, Mikroorganismen und andere infektiöse organische Strukturen wie Viren aber schon sehr viel länger. Wir haben aber erst vor ca. 170 Jahren begonnen, sie überhaupt kennenzulernen, und noch immer kommen neue hinzu. Wir müssen weiter mit ihnen leben und können sie nicht eliminieren, auch nicht diejenigen unter ihnen, die Infektionen verursachen können. Wir können also Infektionsrisiken zwar reduzieren, aber nicht ganz ausschalten.

\section{Aerogene Übertragung}

Es besteht international darin Übereinstimmung, dass der Erreger von COVID-19 - wie andere virale respiratorische Erreger auch - hauptsächlich über große Tröpfchen und Kontakt übertragen wird [6-10,2123]. Neuerdings wird aber auch über die aerogene Übertragung („Aerosole“) diskutiert [23]. Selbst wenn z. B. die Virus-RNA saisonaler Coronaviren in Aerosolen nachgewiesen werden konnte [5], kann daraus nicht geschlossen werden, dass es sich um replikative und infektionstüchtige Viren gehandelt hat [7, 19, 21, 22].

Die Übertragung von SARS-CoV-2 durch infektiöse Aerosole ist derzeit nur eine Hypothese. Ob sie tatsächlich eine relevante Rolle bei der Akquisition dieses Erregers spielen, könnte nur durch sehr sorgfältig geplante Untersuchungen in verschiedenen Settings, inkl. randomisierter kontrollierter Studien, gezeigt werden [7, 23]. So müssten in epidemiologischen Untersuchungen direkte und indirekte Kontakte sicher ausgeschlossen werden, um eine aerogene Übertragung in Betracht ziehen zu können. Der Nachweis von Virus-RNA in Luftproben jedenfalls reicht für eine Bestätigung dieses Übertragungsweges nicht aus, ebenso wenig die Ergebnisse von Untersuchungen, in denen Aerosole experimentell erzeugt, gezählt und vermessen werden oder wenn ihre Verweildauer in solchen experimentellen Situationen bestimmt wird.

\footnotetext{
Merke

Man kann zur Frage der aerogenen Übertragung von Infektionserregern festhalten, dass immer dann, wenn die Möglichkeit einer Übertragung durch die Luft erwogen wird, fast regelmäßig ebenso auch die Übertragung durch direkten oder indirekten Kontakt in Frage kommt.
}

Es handelt sich insgesamt um eine sehr komplexe Fragestellung, die vor allem infektiologische und epidemiologische Faktoren betrifft und die verschiedenen Umgebungsbedingungen (Innenräume, Außenluft) sowie möglicherweise auch aerosolphysikalische Beson- derheiten einschließen muss. So müsste aus infektiologischer Sicht z. B. geklärt werden, ob infektiöse Aerosole überhaupt in ausreichender Zahl an den entscheidenden Stellen in den oberen Atemwegen ankommen, wo SARS-CoV-2 hingelangen muss, weil es sich primär in den Epithelzellen der oberen Atemwege repliziert.

Derartige Überlegungen erfordern eine differenzierte Darstellung in einem eigenen Beitrag. Dabei könnte auch die Frage behandelt werden, welche Rolle MNB (und im Übrigen auch das Abstandsgebot) im öffentlichen Raum spielen würden, wenn die aerogene Übertragung ein Faktum wäre, ob es also weiter um Fremdschutz ginge oder vielleicht der Eigenschutz in den Vordergrund gestellt werden müsste, wofür jedoch nur Atemschutzmasken in Frage kämen und MNB nur noch als begrenzter Fremdschutz dienen könnten (Reduktion der Freisetzung respiratorischer Tröpfchen und dadurch Reduktion der sekundären Entstehung von „Aerosolen“ durch rasches Eintrocknen der kleineren Tröpfchen [21, 22]).

\section{Kontaktübertragung: kontaminierte Hände}

Erreger respiratorischer Infektionen können auch über die eigenen kontaminierten Hände an die Eintrittspforten von Augen, Nase und/oder Mund gebracht werden (sog. Selbstinokulation) [7,21-24]. Dieser Übertragungsweg gehört zu den Kontaktübertragungen (nicht selten immer noch unwissenschaftlich als „Schmierinfektion“ bezeichnet; s. Infobox). Denn es gehört zu den normalen menschlichen Verhaltensweisen, sich oft ins Gesicht zu fassen, z. B. in den Augen oder an der Nase zu reiben.

So ergab eine Beobachtungsstudie bei ca. 250 zufällig ausgewählten Personen in der Öffentlichkeit (z. B. in der U-Bahn), dass ca. 3-4× pro Stunde zunächst irgendwelche Oberflächen und anschließend die Schleimhäute im Gesicht berührt wurden [25]. Die Gelegenheit für eine Kontamination der Hände war demnach viel häufiger, als die Möglichkeit zum Händewaschen im realen Leben überhaupt gegeben ist.

Das RKI legt sich aktuell nicht fest, welchem Übertragungsweg am ehesten die größte Bedeutung zukommt [26]: SARS-CoV-2 werde hauptsächlich respiratorisch übertragen. Dabei werden sowohl Tröpfchen als auch Tröpfchenkerne aufgeführt. Die Kontaktübertragung sei „nicht auszuschließen“ [26].

Umgekehrt kann man über die - z. B. nach Manipulation an der Maske - mit dem eigenen (unerkannt infektiösen) respiratorischen Sekret kontaminierten Hände öffentliche Oberflächen kontaminieren, die dann wiederum von anderen Menschen angefasst werden mit der Folge, dass diese Personen kurz danach mit den nunmehr kontaminierten eigenen Händen das ei- 


\section{DEFINITION}

\section{Von „Schmierinfektion“ zu Kontaktübertragung}

Mit „Schmierinfektion“ ist Kontaktübertragung gemeint. „Schmieren“ - in diesem Zusammenhang im Sinne von „Bestreichen“ verwendet - ist ein Vorgang, durch den es zu einer mit bloßem Auge sichtbaren Auflagerung eines Stoffes kommt (z. B. Butter auf einem Brot, Fingerfarben auf einer Fensterscheibe). „Schmieren“ wird damit der komplexen Problematik der Übertragung von Infektionserregern durch unsichtbare Kontaminationen nicht gerecht: So sehen die Hände des medizinischen Personals in der Regel, z. B. nach der Versorgung eines Patienten, mit bloßem Auge sauber aus, sind aber mikrobiologisch nicht „sauber“ - und müssen deshalb gemäß den Regeln der Standardhygiene (oder „Basishygiene“) vor jedem Patientenkontakt desinfiziert werden.

Der Begriff „Schmierinfektion“ wurde ursprünglich - gewissermaßen als Euphemismus - für die Beschreibung des fäkaloralen Übertragungsweges verwendet und ist im wissenschaftlichen Kontext unüblich (im Übrigen ist der Begriff darüber hinaus nicht korrekt, denn es werden nicht Infektionen übertragen, sondern die jeweils ursächlichen Erreger, die aber noch nicht einmal bei jeder anderen Person zu einer Infektion führen müssen; dasselbe gilt analog für den Begriff „Tröpfcheninfektion“). In der internationalen Fachliteratur gibt es keinen analogen Begriff zu „Schmierinfektion“, ein weiterer Grund, warum heute nur noch von Kontaktübertragung gesprochen werden sollte.

\section{PRAXIS}

\section{Praktischer Hinweis}

Man kann sich also die Hände kontaminieren

- beim direkten Kontakt mit infizierten Menschen, z. B. beim Händeschütteln,

- aber auch bei indirektem Kontakt mit Oberflächen, z. B. Treppengeländern, die von infizierten Menschen angefasst wurden.

gene Gesicht berühren und den Erregern damit die Möglichkeit geben, über die dortigen Schleimhäute einzudringen und in der Folge eine Infektion auszulösen (sämtlich indirekte Kontakte).

So oder so kann man also selbst oder können die Mitmenschen über die meist unbemerkten Hand-Gesichts-Kontakte gerade dort in Kontakt mit Infektionserregern kommen, wo die Erreger respiratorischer Infektionen hingelangen müssen, um eine Infektion erzeugen zu können, nämlich an die Schleimhäute der oberen Atemwege und die Augen (bzw. wo sie sich befinden, falls man schon infiziert ist). Seit Jahrzehnten weiß man im Übrigen, dass respiratorische Viren - ob hüllenlos (wie Rhinoviren) oder behüllt (wie Influenzaund Coronaviren) - auch außerhalb des Körpers für ge- wisse Zeit (abhängig vom Ausmaß ihrer Einbettung in Reste von respiratorischem Sekret) in Zellkulturen anzüchtbar und damit potenziell infektionstüchtig bleiben können [27-29].

Weil man sich also bei verschiedenen Gelegenheiten (im eigenen Haushalt, bei der Arbeit wie auch in der Öffentlichkeit) nahezu ständig die Hände kontaminieren kann und unvermeidlich häufige eigene Hand-Gesichts-Kontakte hat, gehört Händewaschen nach Ansicht aller Gesundheitsbehörden der Welt, wie ebenso z. B. nach den Ergebnissen des Cochrane-Review-Updates von 2011 [30], zu den anerkanntermaßen unverzichtbaren Maßnahmen, um die Übertragung respiratorischer Infektionserreger zu reduzieren.

\section{Merke}

Wenn alle Gesundheitsbehörden der Welt auf die Bedeutung des Händewaschens hinweisen, ist dabei immer gründliches Händewaschen mit Wasser und Seife über 20 - 30 Sekunden gemeint.

\section{Merke}

Aus diesem Grunde weisen alle Gesundheitsbehörden der Welt auf die große Bedeutung der Händehygiene hin, um die Übertragung respiratorischer Viren durch indirekten Kontakt zu reduzieren.

Gleiches gilt für die Prävention gastrointestinaler Infektionen, deren Erreger, z.B. Noroviren, ebenfalls über kontaminierte Hände und nachfolgenden Mundkontakt erworben werden können.

Für die Prävention der Übertragung respiratorischer Erreger bedeutet das aber selbstverständlich auch, dass man sich nicht an oder unter die Maske, fassen soll, weil man dabei seine Hände kontaminieren und damit über Flächenkontakte seine Mitmenschen dem Risiko aussetzen kann, in Kontakt mit den eigenen Erregern zu geraten und so eine Infektion zu bekommen, was doch aber gerade durch die Maske verhindert werden soll.

\section{Nachteile von Masken und Vorsichts- maßnahmen für den Gebrauch}

Alle Gesundheitsbehörden sowie auch das BfArM geben klare und detaillierte Hinweise zum Gebrauch von Masken bzw. zum erforderlichen Umgang mit Masken, damit es nicht durch ihren Gebrauch zu einer Verbreitung des Erregers von COVID-19 kommt [1,6-9].

\section{Kontamination}

Masken werden durch den Träger beim Ausatmen und Sprechen von innen kontaminiert und können durch Handkontakte und respiratorische Tröpfchen anderer Personen ebenso von außen kontaminiert werden. Masken, die im öffentlichen Raum getragen werden, 
sollen als „Fremdschutz“ bzw. „Source Control“ dienen, so die Theorie der Befürworter, d.h. bei Trägern von Masken, die (noch) unerkannt infiziert sind, sollen die beim Sprechen etc. in Töpfchen freigesetzten Erreger von der Maske aufgefangen werden, damit sie möglichst nicht (oder zumindest nicht in großer Zahl) in die Umgebung gelangen.

Bei dieser Annahme ist also die Innenseite der Maske potenziell (denn man weiß ja nicht, ob man schon infiziert ist) mit dem Erreger kontaminiert. Das bedeutet, dass man mindestens bei Kontakt mit der Innenseite der Maske die eigenen Hände mit den - aus dem eigenen Nasen-Rachen-Raum (NRR) bei (noch) unbemerkter Infektion - freigesetzten Erregern kontaminieren kann, ähnlich wie es bei einer Berührung der eigenen Schleimhäute von Augen, Nase oder Mund geschieht. Mit den so möglicherweise kontaminierten Händen berührt man dann wiederum auch öffentliche Oberflächen (z.B. den Griff vom Einkaufswagen oder den Handlauf von Rolltreppen). Anschließend werden diese Oberflächen von anderen Personen ebenfalls angefasst, wodurch es zu einer Verbreitung der Erreger aus dem NRR des Maskenträgers kommen kann.

\section{Durchfeuchtung}

Jede Maske (auch die professionelle medizinische Maske) wird beim längeren Tragen früher oder später durch die Ausatemluft durchfeuchtet und dadurch durchlässig und stellt dann keine Barriere mehr dar. Vielmehr sind die potenziellen Infektionserreger aus dem NRR bei einer durchfeuchteten Maske nicht nur auf der Innenseite zu finden, sondern auch auf der Außenseite. Dies können im Übrigen auch Bakterien sein, wie insbesondere Staphylococcus aureus, einer der häufigsten Erreger eitriger Infektionen von z. B. Zufallswunden.

Auf diese Tatsache weist man in der Krankenhaushygiene das klinisch tätige Personal hin, wie das medizinische Personal im Übrigen auch immer wieder an den korrekten Gebrauch von Masken erinnert wird, z.B. um sich nicht die Hände mit den potenziellen Infektionserregern aus dem eigenen NRR zu kontaminieren, wenn der MNS gegen die Regeln doch um den Hals hängend getragen wird, um ihn später wieder aufsetzen zu können.

\section{Merke}

RKI, ECDC, CDC und WHO betonen mit Nachdruck, dass äußerst sorgfältige Händehygiene und das Vermeiden von Hand-Gesichts-Kontakten essenziell sind und durch den Gebrauch von Masken in der Öffentlichkeit nicht vernachlässigt werden dürfen.

Auch das BfArM hat entsprechende Warnungen und Vorsichtsmaßnahmen beim Umgang mit Masken für die Öffentlichkeit herausgegeben [20]. Ausdrücklich

\section{PRAXIS}

\section{Händewaschen = Infektionsschutz}

Für die Allgemeinbildung der Bevölkerung über individuellen Infektionsschutz - zusätzlich zur Betonung der generellen Notwendigkeit von häufigem Händewaschen - ist der Hinweis notwendig, dass man sich mit den Händen möglichst nicht ins Gesicht fassen soll, solange man die Hände nicht waschen konnte. Das ist nicht leicht, die Häufigkeit solcher Hand-Gesichts-Kontakte lässt sich aber durch eine Schärfung des Bewusstseins reduzieren.

Deshalb sollte man bei Informationskampagnen für die Bevölkerung nicht nur auf die Notwendigkeit von häufigem Händewaschen hinweisen, sondern ausdrücklich auch darauf, warum Händewaschen so sinnvoll und wichtig ist: damit man sich nicht mit kontaminierten Händen an Augen, Nase und Mund fasst.

Dann erst kann die Aufforderung zum Händewaschen wirklich verstanden und nicht (so leicht) als lästige Hygieneregel abgetan werden.

\section{PRAXIS}

\section{Regeln für den Gebrauch von Masken}

Das BfArM hat folgende Regeln für den Gebrauch von Masken formuliert:

- Beim Anlegen der Maske muss darauf geachtet werden, dass die Innenseite nicht kontaminiert wird. Deshalb sollen die Hände zuvor gründlich mit Wasser und Seife gewaschen werden.

- Die Maske muss richtig über Mund, Nase und Wangen platziert sein und an den Rändern möglichst eng anliegen.

- Eine durchgefeuchtete Maske soll umgehend abgenommen und ggf. ausgetauscht werden.

- Die Außenseite der Maske ist potenziell erregerhaltig. Um eine Kontamination der Hände zu verhindern, sollte die Außenseite deshalb möglichst nicht berührt werden.

- Nach Absetzen der Maske sollen die Hände unter Einhaltung der allgemeinen Hygieneregeln gründlich gewaschen werden (mindestens 20 - 30 Sekunden mit Seife).

- Die Maske sollte nach dem Abnehmen in einen Beutel o. Ä. luftdicht verschlossen aufbewahrt oder sofort gewaschen werden. Die Aufbewahrung sollte nur über kurze Zeit erfolgen, um vor allem Schimmelbildung zu vermeiden.

- Masken sollten nach einmaliger Nutzung idealerweise bei $95^{\circ} \mathrm{C}$, mindestens aber bei $60^{\circ} \mathrm{C}$ gewaschen und anschließend vollständig getrocknet werden.

stellt das BfArM fest, dass Träger von Community-Masken sich nicht darauf verlassen können, dass die Masken sie oder andere vor einer Übertragung durch SARS-CoV-2 schützen, da für diese Masken keine entsprechende Schutzwirkung nachgewiesen wurde. 


\section{Schlussfolgerungen für die Anwendung von Masken im öffentlichen Raum}

Merke

Der Gebrauch von Masken im öffentlichen Raum ist schon allein aufgrund des Fehlens von wissenschaftlichen Daten fragwürdig. Zieht man dazu noch die erforderlichen Vorsichtsmaßnahmen in Betracht, müssen Masken nach den aus Krankenhäusern bekannten Regeln im öffentlichen Raum sogar als ein Infektionsrisiko betrachtet werden.

Werden Masken von der Bevölkerung getragen, ist also potenziell das Infektionsrisiko erhöht, ganz gleich, ob es medizinische Masken sind oder ob es sich um wie auch immer gestaltete sog. Community-Masken handelt. Betrachtet man die Vorsichtsmaßnahmen, die das RKI wie ebenso die internationalen Gesundheitsbehörden ausgesprochen haben, müssten alle Behörden die Bevölkerung sogar dahingehend informieren, dass Masken im öffentlichen Raum möglichst gar nicht getragen werden sollen. Denn ganz gleich, ob Pflicht für alle Bürger oder freiwillig getragen von den Bürgern, die das aus welchen Gründen auch immer wollen, bleibt es ein Faktum, dass Masken in der Öffentlichkeit mehr Schaden als Nutzen bringen können.

\section{Wie sieht die Realität beim Umgang mit Masken in der Öffentlichkeit aus?}

Ein korrekter Umgang mit Masken ist beim medizinischen Personal, wie bereits erwähnt, nicht immer leicht zu erreichen. Bei der Bevölkerung aber sind alle diese als unverzichtbar angesehenen Anforderungen auch nicht im Ansatz zu verwirklichen. So ist beim Einkaufen z. B. zu beobachten:

- Die Maske wird häufig mit den Händen zurechtgerückt.

- Sie wird oft so getragen, dass die Nase unbedeckt ist.

- Sie ist für Brillenträger besonders problematisch, weil die Brille beschlägt, denn im Gegensatz zu einem professionellen chirurgischen MNS fehlt bei der Community-Maske in der Regel ein leicht biegsamer Bügel, den man gut an die Anatomie der Nase anpassen kann. Man muss also die Brille wiederholt abnehmen und aufsetzen und berührt dabei unvermeidlich mit den Händen die Außenseite der Maske.

- Auch wenn nicht besonders warmes Wetter herrscht, schwitzt man unter der Maske und geht von daher auch immer wieder mit den Händen an die Maske oder sogar darunter.

- Außerhalb der Läden wird die Maske häufig nur teilweise abgenommen und hängt dann mit einer Schlinge über einem Ohr, wird unter das Kinn geschoben oder sie wird abgenommen und einfach in die Hand-, Hosen- oder Jackentasche gesteckt. Fer- ner kann man beobachten, dass die Maske, um stets griffbereit für den nächsten Gebrauch zu sein, im Auto am Rückspiegel hängt (immerhin hängt sie dort wenigstens luftig).

Man muss sich allerdings auch fragen, wie man es unterwegs auch anders machen soll, selbst wenn man bemüht ist, seine Hände möglichst nicht an der Maske zu kontaminieren:

- Man kann sich nicht die Hände waschen, wenn man aus dem Auto steigt und vor Betreten des Ladens die Maske aufsetzen muss, und man kann sich auch nach Verlassen des Ladens, wenn die Maske wieder abgesetzt wurde, nicht die Hände waschen.

- Da Händedesinfektionsmittel (HDM) ebenso wie medizinische Masken und andere Schutzausrüstung in den medizinischen Einrichtungen zwischenzeitlich zur Mangelware geworden sind, kann man dies auch nicht mit dem Gebrauch von HDM unterwegs kompensieren, und das RKI empfiehlt dies auch nicht. Denn auch Händedesinfektion muss gelernt sein und ist keineswegs trivial.

Die nächste Frage ist, wie man es bewerkstelligen soll, die Masken nach jedem Gebrauch zu verwerfen (oder bis zum Waschen zu Hause in einen Beutel zu packen), wenn man in mehrere Geschäfte gehen muss:

- Man müsste dann immer mehrere Masken bei sich haben.

- Eine andere Möglichkeit wäre, die Maske nach Verlassen eines Geschäfts einfach aufzulassen, wie man es bei manchen Menschen beobachten konnte. Dann könnte man alle Besorgungen (und die Wege dazwischen, wenn es Fußwege sind) mit einer einzigen Maske machen. Die Menschen laufen dann im Freien mit einer Maske herum, wo sie gar nicht vorgeschrieben ist.

- Es ist wahrscheinlich, dass das Maskenmaterial während der Einkäufe durchfeuchtet, denn insbesondere durch die Pflicht, überall den Mindestabstand von 1,5 m einzuhalten, wird das Einkaufen umständlicher und dauert somit deutlich länger, z. B. weil man im Laden nicht mal schnell an anderen Kunden vorbeigehen darf, sondern warten muss, bis entsprechend Platz zum Überholen ist.

- Wenn man aber den Weg zwischen den Läden mit dem Auto zurücklegen muss, dann muss die Maske abgelegt werden, weil man „maskiert“ nicht Auto fahren darf.

\section{Unerfüllbare Forderungen}

Im Alltag ist das eine unlösbare Aufgabe, will man zig Millionen Bürger dazu bringen, diese notwendigen Vorsichtsmaßnahmen beim Gebrauch von Masken einzuhalten, wenn das schon beim medizinischen Personal nicht ganz einfach ist, wo aber mit dem Hygienefachpersonal (Hygienefachkräfte, Krankenhaushygieniker) 
immer Personen vor Ort an den richtigen Umgang erinnern können: Es ist wirklichkeitsfremd.

Deshalb ist die MNB-Empfehlung des RKI nicht damit zu rechtfertigen, dass auf die erforderlichen Vorsichtsmaßnahmen hingewiesen wird, und zwar, weil es sich um unerfüllbare Forderungen handelt, die zwangsläufig und für alle Fachleute erkennbar nicht umgesetzt werden (können).

\section{FAZIT}

Aus einer Maskenpflicht für viele Millionen Bürger in Deutschland können jeden Tag zig-millionenfache Kontaminationen resultieren, die zu einem wesentlichen Teil vermeidbar wären, weil die ohnehin schon häufigen Hand-Gesichts-Kontakte der Menschen durch die Maskenpflicht noch häufiger werden, Händewaschen unterwegs aber nur ausnahmsweise möglich ist. Dabei besteht das Risiko, dass der - schon zwangsläufig - unsachgemäße Umgang mit der Maske und die erhöhte Tendenz, sich selbst ins Gesicht zu fassen, während man die Maske trägt, tatsächlich das Risiko einer Erregerverbreitung und damit Erregerübertragung noch erhöht - ein Risiko, das man doch aber gerade durch die Maske reduzieren will.

Eine Maskenpflicht vermittelt ein falsches Sicherheitsgefühl, und ein falsches Sicherheitsgefühl ist immer ein Sicherheitsrisiko.

\section{Schlussfolgerungen}

Die Empfehlung für MNB im öffentlichen Raum hat

1. keine wissenschaftliche Grundlage und ist

2. sogar potenziell kontraproduktiv.

Angesichts der niedrigen Inzidenz von COVID-19 (Juli 2020) und somit auch angesichts der Tatsache, dass eine Überlastung des Medizinsystems und insbesondere der Intensivbehandlungskapazität nicht zu erwarten ist (und im Übrigen auch in den Wochen zuvor nicht gegeben war), ist eine so einschneidende Maßnahme wie die generelle Maskenpflicht für die bei weitem überwiegende Mehrheit aller Bürger im öffentlichen Raum nicht zu begründen und entspricht auch nicht den Empfehlungen der WHO.

\section{KERNAUSSAGEN}

- Bei zahlreichen Virusinfektionen beginnt die Erregerausscheidung am Ende der Inkubationszeit, also bevor Krankheitssymptome zu bemerken sind. Dies ist z. B. auch von der Influenza bekannt, weshalb man auch bei COVID-19 schon zu Beginn der Pandemie davon hätte ausgehen können.

- Bei Auswertung der vom RKI für dessen „Neubewertung“ von Masken im öffentlichen Raum angeführten Publikationen zeigt sich, dass es keine wissenschaftliche Grundlage gibt, mit der der Gebrauch von Masken (gleich welcher Art) in der Öffentlichkeit bei nahezu der gesamten Bevölkerung von Deutschland (abzüglich der Kinder bis 6 Jahre ca. 80 Mio. Menschen) gerechtfertigt werden kann, und aktuelle Untersuchungen zeigen das Gleiche.

- Im Gegenteil kann eine Maskenpflicht für viele Millionen Menschen im öffentlichen Raum sogar zu einem Infektionsrisiko werden, weil die erforderliche Händehygiene nicht eingehalten werden kann.

- Indirekte Erregerkontakte über kontaminierte Oberflächen werden durch Masken nicht weniger, sondern kommen im Gegenteil potenziell häufiger zustande als ohne Masken.

- Bei der Übertragung respiratorischer Viren spielt ein enger ( $<1 \mathrm{~m}$ ) Face-to-Face-Kontakt die entscheidende Rolle, der zudem mindestens über eine gewisse Zeit ( $\geq 15 \mathrm{~min}$ ) bestehen muss, damit sich ein Übertragungsrisiko überhaupt verwirklichen kann.

- Die meisten Kontakte im öffentlichen Raum sind zum einen keine Face-to-Face-Kontakte. Zum anderen dauern sie, selbst wenn sie dennoch stattfinden, meist kürzer als 15 min, sodass eine effektive Übertragung infektiöser Tröpfchen in diesen Situationen sehr unwahrscheinlich erscheint.

- Abstand halten bei Gesprächen schützt vor direkten Erregerkontakten und macht das Tragen von Masken überflüssig.

Interessenkonflikt

Erklärung zu finanziellen Interessen

Forschungsförderung erhalten: nein; Honorar/geldwerten Vorteil für Referententätigkeit erhalten: nein; Bezahlter Berater/interner Schulungsreferent/Gehaltsempfänger: nein; Patent/Geschäftsanteile/Aktien (Autor/Partner, Ehepartner, Kinder) an Firma (Nicht-Sponsor der Veranstaltung): nein; Patent/Geschäftsanteile/Aktien (Autor/Partner, Ehepartner, Kinder) an Firma (Sponsor der Veranstaltung): nein.

Erklärung zu nichtfinanziellen Interessen

Die Autorinnen/Autoren geben an, dass kein Interessenkonflikt besteht. 


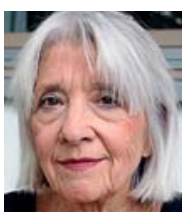

\section{Ines Kappstein}

Prof. Dr. med. Medizinstudium in Freiburg, danach Tätigkeit am Institut für Allgemeine Hygiene und Bakteriologie, Chirurgische Universitätsklinik Freiburg, Facharztausbildungen für Mikrobiologie, Virologie und Infektionsepidemiologie sowie für Hygiene und Umweltmedizin. 1993 Habilitation im Fach Krankenhaushygiene. 1998-2006 Tätigkeit im Klinikum rechts der Isar der TU München. 2006-2016 Chefärztin der Abteilung Krankenhaushygiene an den Kliniken Südostbayern AG der Landkreise Traunstein und Berchtesgadener Land. Seit 2016 Betreuung mehrerer Akut-, Fach- und Reha-Kliniken in selbstständiger Tätigkeit.

\section{Korrespondenzadresse}

Prof. Dr. med. Ines Kappstein

Krankenhaushygiene-Kappstein@t-online.de

Literatur

[1] Robert Koch-Institut - RKI. Mund-Nasen-Bedeckung im öffentlichen Raum als weitere Komponente zur Reduktion der Übertragungen von COVID-19. Epid Bull 2020; 19: 3-5

[2] Robert-Koch-Institut. Influenza (Teil 1): Erkrankungen durch saisonale Influenzaviren. Robert-Koch-Institut; 2018: Im Internet: (Stand: 19.01.2018) https://www.rki.de/DE/ Content/Infekt/EpidBull/Merkblaetter/Ratgeber_Influenza_saisonal.html

[3] Ebner W, Meyer E. Noroviren. KHHu2d 2017; 2: 9-20

[4] Cheng KK, Lam TH, Leung CC. Wearing face masks in the community during the COVID-19 pandemic: altruism and solidarity. Lancet 2020: 395doi: 10.1016/S0140-6736(20) 30918-1

[5] Leung NHL, Chu DKW, Shiu EYC et al. Respiratory virus shedding in exhaled breath and efficacy of face masks. Nature Med 2020: 1-20

[6] World Health Organization - WHO. Non-pharmaceutical public health measures for mitigating the risk an impact of epidemic and pandemic influenza. WHO; 2019: Im Internet: (Stand: 07.07.2020) https://www.who.int/influenza/ publications/public_health_measures/publication/en/

[7] World Health Organization (WHO). Advice on the use of masks in the context of COVID-19 (5. Juni 2020).https:// www.who.int/publications-detail/advice-on-the-use-ofmasks-in-the-community-during-home-care-and-in-healthcare-settings-in-the-context-of-the-novel-coronavirus(2019-ncov)-outbreak (Stand: 07.07.2020)

[8] European Centre for Disease Prevention and Control (ECDC). Using face masks in the community (8. April 2020). https://www.ecdc.europa.eu/sites/default/files/documents/COVID-19-use-face-masks-community.pdf (Stand: 07.07.2020)

[9] Centers for Disease Control and Prevention (CDC). https:// www.cdc.gov/coronavirus/2019-ncov/prevent-gettingsick/cloth-face-cover.html (Stand: 07.07.2020)
[10] Jefferson T, Jones MA, Al-Ansary L et al. Physical interventions to interrupt or reduce the spread of respiratory viruses. Part 1: Face masks, eye protection and person distancing: systematic review and meta-analysis.https://www.medrxiv. org/content/10.1101/2020.03.30.20047217v2 (Stand: 07.07.2020)

[11] Rancourt DG. Masks don't work - A review of science relevant to COVID-19 social policy.https://www.researchgate. net/publication/340570735_Masks_Don't_Work_A_review_of_science_relevant_to_COVID-19_social_policy (Stand: 07.07.2020)

[12] Brainard J, Jones N, Lake I et al. Facemasks and similar barriers to prevent respiratory illness such as COVID-19: a rapid systematic review. medRxiv 2020: doi: 10.1101/ 2020.04.01.20049528

[13] Deutsche Gesellschaft für Pneumologie (DGP). Stellungnahme der DGP zur Auswirkung von Mund-Nasenmasken auf den Eigen- und Fremdschutz bei aerogen übertragbaren Infektionen in der Bevölkerung. Pneumologie , Online-Publikation 2020: doi: 10.1055/a-1175-8578

[14] Mitze T, Kosfeld R, Rode J et al. Face masks considerably reduce COVID-19 cases in Germany: a synthetic control method approach. IZA Institute of Labour Economics, IZA DP Nr. 13319062020

[15] Buchholz U, Buda S, Prahm K. Abrupter Rückgang der Raten an Atemwegserkrankungen in der deutschen Bevölkerung. Epid Bull 2020; 16: 7-9

[16] an der Heiden M, Hamouda O. Schätzung der aktuellen Entwicklung der SARS-CoV-2-Epidemie in Deutschland Nowcasting. Epid Bull 2020; 17: 10-16

[17] Zhang R, Li Y, Zhang AL et al. Identifying airborne transmission as the dominant route for the spread of COVID-19. www.pnas.org/cgi/doi/10.1073/pnas.2009637117

[18] Eikenberry SE, Mancuso M, Iboi E. To mask or not to mask: Modelling the potential for face mask use by the general public to curtail the COVID-19 pandemic. Infectious Disease Modelling 2020; 5: 293-308

[19] Chu DK, Akl EA, Duda S et al. Physical distancing, face masks, and eye protection to prevent person-to-person transmission of SARS-CoV-2 and COVID-19: a systematic review and meta-analysis. Lancet 2020: Published Online June 1, 2020. Im Internet: (Stand: 07.07.2020) doi: 10.1016/S0140-6736(20)31142-9

[20] Bundesinstitut für Arzneimittel und Medizinprodukte (BfArM). Hinweise des BfArM zur Verwendung von selbst hergestellten Masken (sog. „Community-Masken“), medizinischem Mund-Nasen-Schutz (MNS) sowie filtrierenden Halbmasken (FFP2 und FFP3) im Zusammenhang mit dem Coronavirus (SARS-CoV-2 / Covid-19). 31.03 2020: Im Internet: (Stand: 07.07.2020) https://www.bfarm.de/SharedDocs/Risikoinformationen/Medizinprodukte/DE/schutzmasken.html

[21] Schulze-Röbbecke R. Nosokomiale Infektionen: Übertragungswege und Übertragungsprävention. KHHu2d 2018; 13: $63-75$

[22] Schulze-Röbbecke R, Reska M, Lemmen S. Welche Schutzmaske schützt vor COVID-19? Was ist evidenzbasiert? KHHu2d 2020; 15: 123-132 Online-first

[23] World Health Organization (WHO). Transmission of SARS CoV-2: implications for infection prevention precautions. https://www.who.int/publications/i/item/modes-of-transmission-of-virus-causing-covid-19-implications-for-ipcprecaution-recommendations 
[24] Gwaltney M, Moskalsky PB, Hendley JO. Hand-to-hand transmission of rhinovirus colds. Ann Int Med 1978; 88: 463-467

[25] Alonso W], Nascimento FC, Shapiro J et al. Facing ubiquitous viruses: when handwashing is not enough (Correspondence). Clin Infect Dis 2013; 56: 617

[26] Robert-Koch-Institut. Steckbrief zur Coronavirus-Krankheit2019 (COVID-19. Robert-Koch-Institut; 2020: Im Internet: (Stand: 10.7.2020) ttps://www.rki.de/DE/Content/InfAZ/N/ Neuartiges_Coronavirus/Steckbrief.html\#doc13776792bodyText1

[27] Hall CB, Douglas RG]r, Geiman JM. Possible transmission by fomites of respiratory syncytial virus. J Infect Dis 1980; 141: 98-102

[28] Hall CB. Nosocomial respiratory syncytial virus infections: The „cold war' has not ended. Clin Infect Dis 2000; 31: 590596

[29] Dietz L, Horve PF, Coil DA et al. 2019 novel coronavirus (COVID-19) pandemic: built environment considerations to reduce transmission (Minireview). Msystems 2020; 5 : e00245-20 Im Internet: (Stand: 07.07.2020) https://doi. org/10.1128/mSystems.00245-20
[30] Jefferson T, Del Mar CB, Dooley L et al. Physical interventions to interrupt or reduce the spread of respiratory viruses. Cochrane Database Syst Rev 2011: Im Internet: (Stand: 07.07.2020) https://www.cochranelibrary.com/cdsr/doi/ 10.1002/14651858.CD006207.pub4/full

Bibliografie

DOI https://doi.org/10.1055/a-1174-6591

Krankenhaushygiene up2date 2020; 15: 279-295

(c) Georg Thieme Verlag KG Stuttgart · New York ISSN 1862-5797 